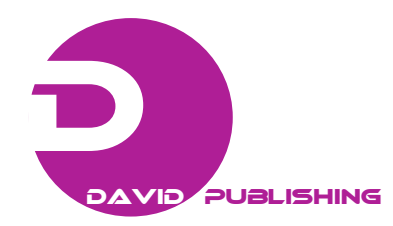

\title{
Separation of Soybean Oil/n-hexane Miscellas Using Polymeric Membranes
}

\author{
Marcus V. Tres ${ }^{1}$, Jéssica C. Racoski ${ }^{1}$, Zuleica Novello ${ }^{1}$, Jonas R.M. de Melo ${ }^{1}$, Helen C. Ferraz ${ }^{2}$, Marco Di \\ Luccio $^{1}$ and José Vladimir Oliveira ${ }^{1}$ \\ 1. Department of Food Engineering, URI-Campus de Erechim, Av. Sete de Setembro, 1621, Erechim 99700-000 RS, Brazil \\ 2. Program of Chemical Engineering, COPPE, UFRJ-Centro de Tecnologia, Bloco G, Sala 115, Rio de Janeiro 21941-972, RJ, \\ Brazil
}

Received: August 29, 2012 / Published: November 20, 2012.

\begin{abstract}
Separation of refined soybean oil/n-hexane miscellas was studied using different commercial ultra- and nanofiltration membranes, with cut-offs in the range of 1 to $5 \mathrm{kDa}$ and salt rejection higher than $97 \%\left(\mathrm{MgSO}_{4}\right)$. Commercial soybean oil and n-hexane miscellas with 1:3 and 1:1 mass ratios were permeated in a dead-end module. The effects of the feed pressure (2-25 bar) on oil and $\mathrm{n}$-hexane fluxes and rejection were investigated. Oil rejection ranged from negative values to $30.8 \%$, soybean oil flux from 28.9 to $617.8 \mathrm{~g} / \mathrm{m}^{-2} \mathrm{~h}^{-1}$ and $\mathrm{n}$-hexane flux from 8.5 to $1,078.5 \mathrm{~g} \mathrm{~m}^{-2} \mathrm{~h}^{-1}$. Membrane fouling was observed at all experimental conditions studied. The membrane separation process has proven to be a promising alternative to solvent recovery in soybean oil extraction.
\end{abstract}

Key words: Soybean oil, n-hexane, ultrafiltration, nanofiltration, polymeric membranes.

\section{Introduction}

Edible oils and fats are renewable resources worldwide available with many different applications. However, despite few exceptions, the crude oil cannot be commercially used without further processing. The crude edible oils need to be refined to meet suitable properties for commercial applications. This process involves removing unwanted components and concentration of desired substances. Edible oils are usually extracted using n-hexane, therefore demanding a step of solvent removal from the oil [1].

Expensive and time-consuming processes, such as distillation, must be used to remove n-hexane from the oil and the residue. The initial vegetable oil processing step consists on the extraction of oil from oilseeds. The type of processing depends on the initial oil content of the material to be processed. For raw materials with oil content below $20 \%$, e.g., soybean, solvent extraction is

Corresponding author: Marcus V. Tres, Ph.D., research fields: membrane separation process, supercritical extraction. E-mail: marcusvtres@gmail.com. commonly used [1]. The oilseed extractions by organic solvents have been defined as a process of mass transfer from one phase to another with the proposal to separate one or more components of the miscella. In the case of oil extraction from oilseeds, raw vegetable oils are separated from the cake by the solvent, along with proteins and carbohydrates [2].

The solvent extraction process is the most widely used and most efficient in terms of residual oil in the cake, expending approximately $20-25 \mathrm{~kW} \mathrm{~h}^{-1}$ per ton of soybean processed, and producing a cake containing about $0.8 \%$ oil [3].

Hexane recovery is carried out in two parallel steps: the separation of hexane from the cake (bran), called desolventizing-toasting and its removal from the miscella ( $20 \%-30 \%$ by mass of the oil), called miscella distillation. Solvent removal toasting is an operation with various stages where the bran is the first put in direct contact with water vapor for hexane stripping. Increasing the moisture content and toasting of the bran, with the additional objective of inactivating anti-nutritional 
factors naturally present in the soybean $[4,5]$.

Membrane technology is still evolving, with increasingly applications found in food processing. Conventional membrane processes such as microfiltration, ultrafiltration and reverse osmosis are currently being considered as standard unit operations, and are being implemented in numerous processes [6]. With respect to the food industry, the focus of this technology is presently on the production of more adequate membranes for particular processes and products, or even to improve the quality of existing products [7].

The studies on the use of membrane technology for oil processing are mostly directed at solvent recovery from the miscella, degumming, bleaching, deacidification, hydrolysis of fats and oils, synthesis of structured lipids in membrane reactors, concentration of minor compounds and the separation of emulsions [8]. The major potential for energy savings due to the application of membrane processes in the oil production lies on the replacement of the conventional degumming, refining and bleaching processes by membrane processes, or even on the use of hybrid processes. Bleaching and degumming could be combined into a single energy-efficient step. Reduced oil losses and bleaching agent requirements are other potential advantages of membrane processing. An ideal membrane for solvent recovery should combine specific properties such as high oil rejection and permeate fluxes that are adequate for industrial scale, as well as mechanical, thermal and chemical resistances, compatible with the process [9].

In contrast to the conventional refining process, membrane processes can be carried out at low temperatures, preserving the heat-sensitive oil constituents of technological interest, such as the natural antioxidants. A more stable and consequently better-quality product can be obtained using membranes [7].

The present report is part of a broader project aiming at developing new membrane-based separation processes applied to oil-solvent miscellas operated at low and intermediate pressures [10-12]. Here, the main objective is to select and explore the application of commercial ultrafiltration and nanofiltration membranes for the separation of soybean oil from miscellas of this oil in n-hexane. The final purpose is directed at the application of this technology to aid solvent recovery in the oil extraction plants.

\section{Material and Methods}

\subsection{Membranes}

Permeation using miscellas of commercial refined soybean oil and n-hexane (Vetec, 99\% purity) was carried out in a stainless-steel dead-end flow module (capacity $500 \mathrm{~mL}$ ) with membrane area of $35.3 \mathrm{~cm}^{2}$. Table 1 presents the characteristics of the membranes used in this study.

\subsection{Membrane Conditioning}

Membrane conditioning is an important step in the separation process, since the conditioning can change

Table 1 Membrane specifications.

\begin{tabular}{lllllll}
\hline Class $^{\mathrm{a}}$ & Supplier & Membrane material & Trade name & $\begin{array}{l}\mathrm{MWCO}^{\mathrm{b}} \\
\text { rejection }\end{array}$ & pH range $\left(25^{\circ} \mathrm{C}\right)$ & $\begin{array}{l}\text { Typical water flux }^{\mathrm{c}} \\
\left(\mathrm{L} /\left(\mathrm{m}^{2} \mathrm{~h}\right)\right)\end{array}$ \\
\hline UF & GE-Osmonics & Composite polyamide & Sepa GE & $1 \mathrm{kDa}$ & $2-11$ & 30.6 at $27.6 \mathrm{bar}$ \\
UF & GE-Osmonics & Poly(amide)/Poly(sulfone) $)^{\mathrm{d}}$ & Sepa GM & $4 \mathrm{kDa}$ & $2-11$ & 34 at $2.8 \mathrm{bar}$ \\
$\mathrm{UF}$ & GE-Osmonics & Poly(ethersulfone $)$ & Sepa PT & $5 \mathrm{kDa}$ & $2-11$ & 153 at $3.4 \mathrm{bar}$ \\
$\mathrm{NF}$ & DOW-Filmtec & Pol(yamide)/Poly(sulfone) $)^{\mathrm{d}}$ & $\mathrm{NF} 90$ & $>97 \% \mathrm{MgSO}_{4}$ & $2-11$ & - \\
\hline
\end{tabular}

${ }^{\mathrm{a} U F}$ : ultrafiltration; NF: nanofiltration;

${ }^{\mathrm{b}}$ Molecular weight cut-off;

${ }^{\mathrm{c}}$ According to supplier data sheet;

${ }^{\mathrm{d}}$ Exact composition not informed. 
the membrane polarity $[13,14]$, cause a clustering effect on hydrophobic and hydrophilic groups on the membrane top layer [15] and remove preservatives and humectants from the membrane surface and its pores [16].

Based on a previous work [10], the organic solvent chosen to condition, the membranes were ethanol (99.8\%, Vetec). Before the experiments, the membranes were cut into flat discs and immersed in the solvent for $24 \mathrm{~h}$.

\subsection{Permeation Procedure}

Refined soybean oil/n-hexane miscellas with mass ratio $1: 3$ and 1:1 were used in the feed, since these are typical ratios found in the soybean oil processing. Three hundred grams of the miscella were used in each experiment. The experimental conditions investigated in this work are presented in Table 2. The feed pressure varied from 2 to $25 \mathrm{bar}$, achieved by pressurization of the dead-end cell with gaseous nitrogen. The choice of the feed pressure was based on the different pore sizes of the membranes. The feed solution was stirred at 300 rpm inside the module at room temperature (approximately $20^{\circ} \mathrm{C}$ ). The samples of permeate were collected in glass vials, immediately weighed and the solvent was evaporated at $65^{\circ} \mathrm{C}$ until a constant weight was achieved (approximately $20 \mathrm{~h}$ ). Oil concentration was calculated based on gravimetric results. The samples were also analyzed in a digital densimeter (Anton Paar DMA 4500), and oil concentration was calculated using a calibration curve. All permeation runs were carried out at least in duplicates, and experimental error was always below $5 \%$.

\section{Results and Discussion}

\subsection{Membrane Permeations}

The changes in the total flux with time, for the oil/n-hexane feed ratios $1: 3$ and $1: 1$, are presented in Figs. 1-4. A flux decrease with time was observed for all membranes, which is a typical behavior of concentration polarization and membrane fouling.
Table 2 Permeation conditions.

\begin{tabular}{|c|c|c|}
\hline Membrane & Oil/n-hexane ratio (wt) & Feed pressure (bar) \\
\hline Sepa GE (1 kDa) & $1: 3 / 1: 1$ & $15-25$ \\
\hline Sepa GM (4 kDa) & $1: 3 / 1: 1$ & $2-10$ \\
\hline Sepa PT (5 kDa) & $1: 3 / 1: 1$ & $2-10$ \\
\hline NF90 & $1: 3$ & $15-25$ \\
\hline
\end{tabular}

Usually, the magnitude of this flux loss depends on several factors such as the membrane nature, feed concentration, temperature and hydrodynamic conditions [17]. A straightforward comparison of permeate fluxes with those reported in literature $[9,16]$ is rather difficult, because membrane material and supplier are different, and differences in membrane pore size, pore distribution, material can cause the observed differences.

For Sepa PT, the decrease in flux with time is much smaller than for the other tested membranes. This membrane has larger pores and therefore less polarization of the oil in its surface due to lower rejection. It is interesting to note that for NF90, Sepa GE and Sepa GM (this latter only in the feed 1:3) the flux at different operating pressures tends to a limiting flux, although this effect is more pronounced in NF90.

The increase of operating pressure can lead to increased permeate flux, which is observed for lower pressures. However, the increase of permeate flux causes a greater concentration of species trapped near the surface of the membrane, which tends to cause a drop in permeate flux. Thus, from a certain pressure, the increase in the pressure corresponds to an equivalent increase in resistance to solvent transport due to concentration polarization. The consequence is that the flux remains unchanged with increasing pressure. Other authors report this behavior, which is known as limiting flux [18, 19]. In practice, any membrane system should be operated at pressures below this point [20]. The membrane samples attained the limiting flux regardless of their initial flux or applied pressure. On the other hand, little foulant deposition occurs for membrane samples whose initial flux was below the limiting value (Sepa PT, Figs. 4 and 5). 


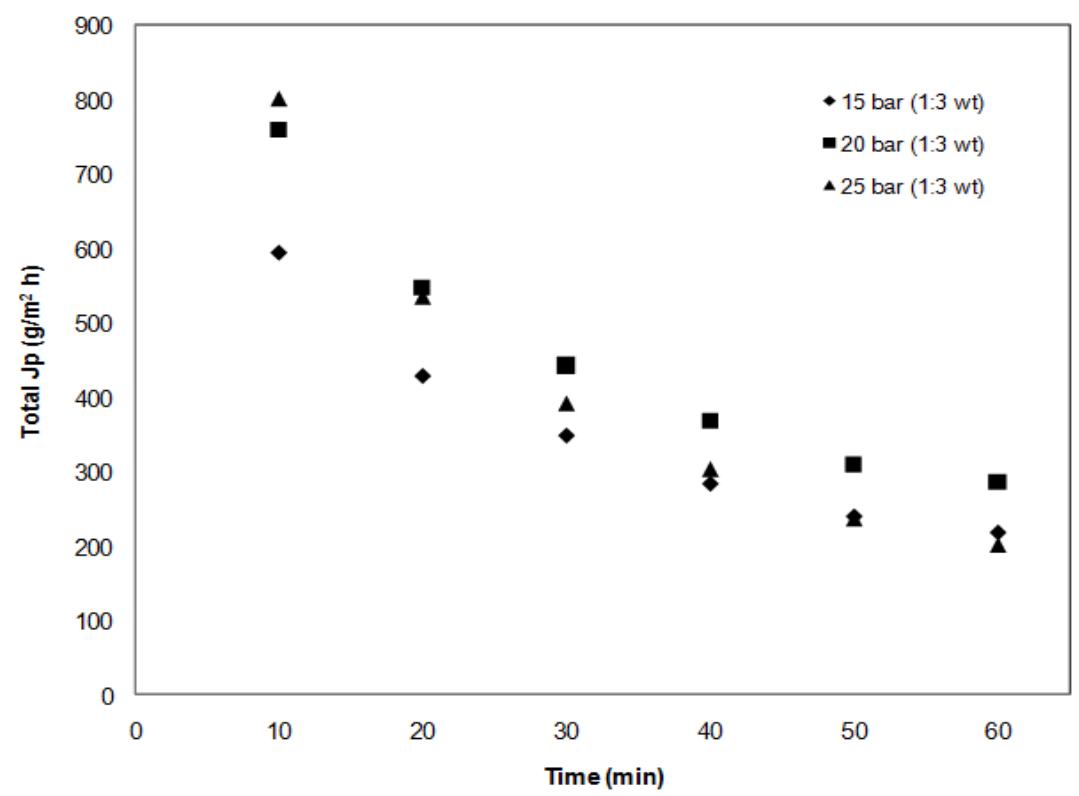

Fig. 1 Total permeate fluxes for NF 90 membrane, feed concentration 1:3 (oil/n-hexane).

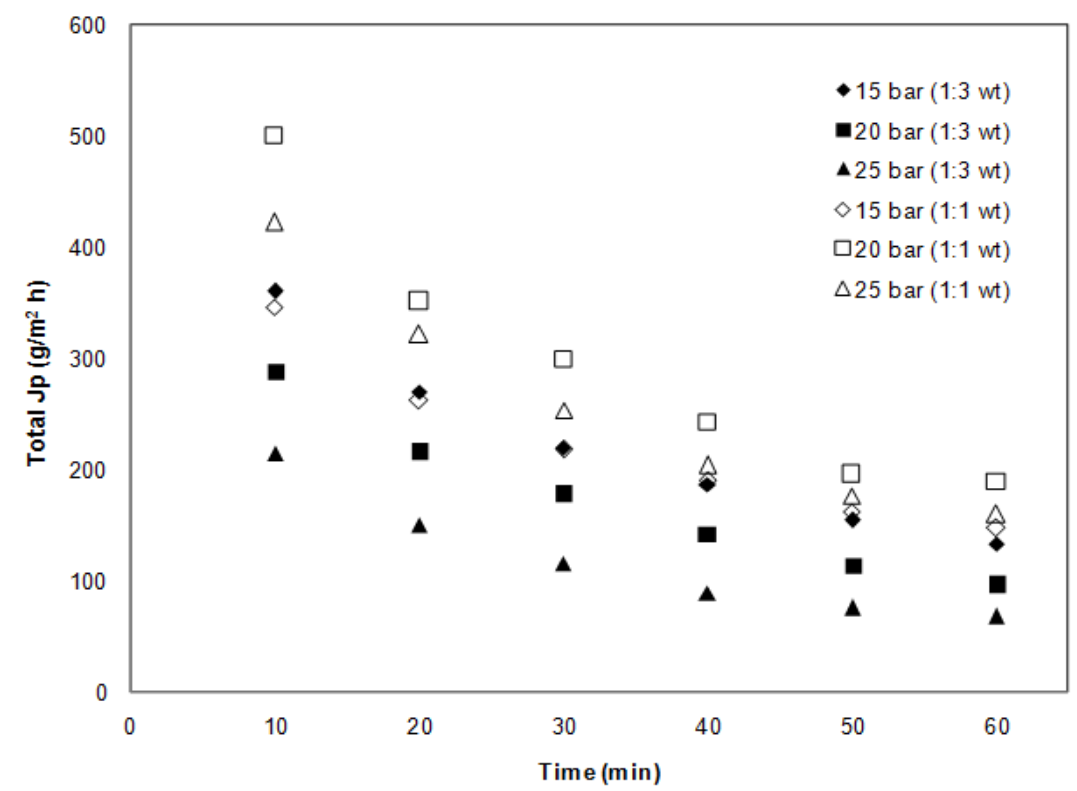

Fig. 2 Total permeate fluxes for Sepa GE membrane.

The limiting flux does not depend on the properties of membranes, i.e., the limiting flux is independent on the foulant-membrane interaction. In contrast, Tang and Leckie [19] said that the critical flux is affected by membrane properties. The limiting flux can be considered as an upper-bound of the critical flux. The limiting flux depends strongly on the feed composition. This can be observed when we compare the results in Figs. 2 and 3 with Figs. 6 and 7. Membranes Sepa GE and Sepa GM showed higher limiting fluxes when operated at higher feed concentrations.

Generally, the increase in pressure led to an increase in oil and n-hexane fluxes, except for Sepa GE. This result might be related with the chemical nature of the membrane that could be inducing to higher fouling. The decrease on oil permeate flux over time can be explained by the material on the membrane surface that can become compacted or precipitate, forming a layer 


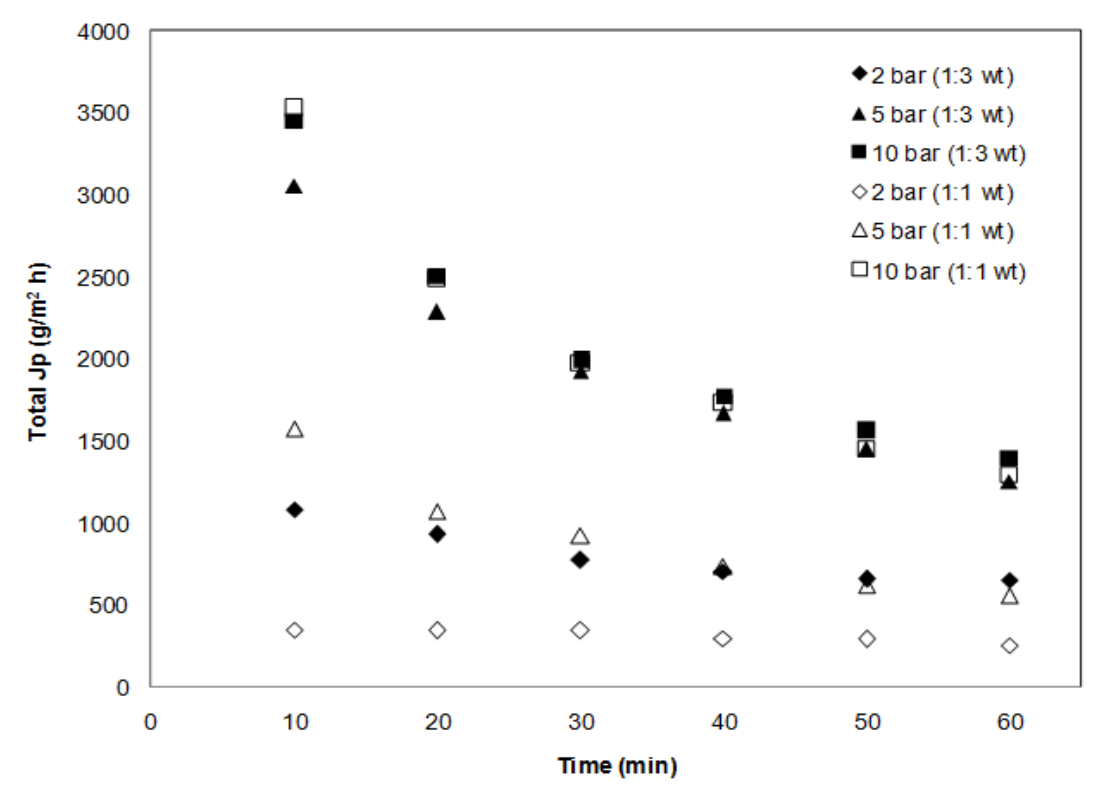

Fig. 3 Total permeate fluxes for Sepa GM membrane.

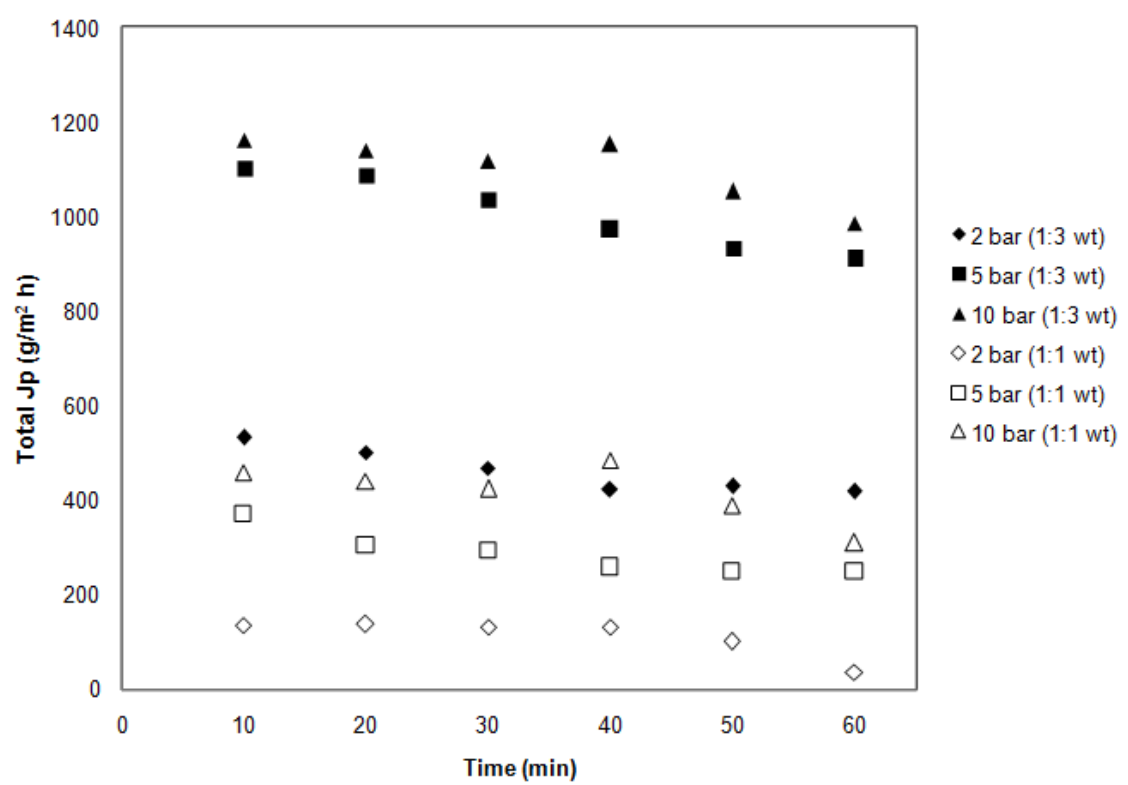

Fig. 4 Total permeates fluxes for Sepa PT membrane.

of deposited material that has a lower permeability [21]. The effect of membrane compaction may also be considered, which might have the effect of reducing the membrane pore diameter, mainly when using higher pressures. The fouling effects cannot be completely avoided, but can be reduced through the use of membranes with a proper cut-off and hydrophobicity/hydrophilicity characteristics suitable for the separation, as shown in the present work [22].
The effect of the concentration of oil in the feed could also be depicted from Figs 1-4. Membrane rejections to oil are presented in Figs. 5-7. Similarly to the flux results, the rejections change with time, due to concentration polarization and fouling effects. An increase in the oil rejection as a function of the process time is observed for the most membranes. This may be attributed to a membrane pore blockage, thus increasing its selectivity. This effect is less observed in 


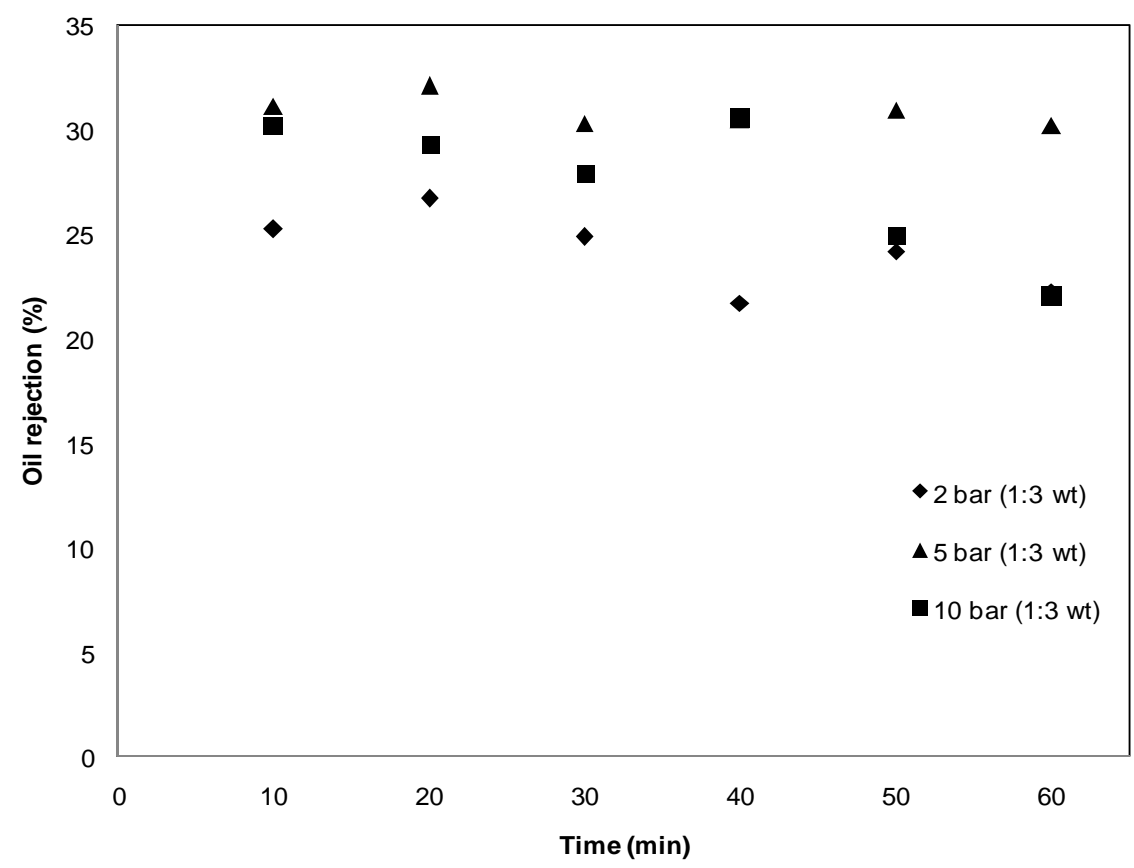

Fig. 5 Soybean oil rejection (\%) for Sepa PT membrane, feed concentration 1:3 (oil/n-hexane).

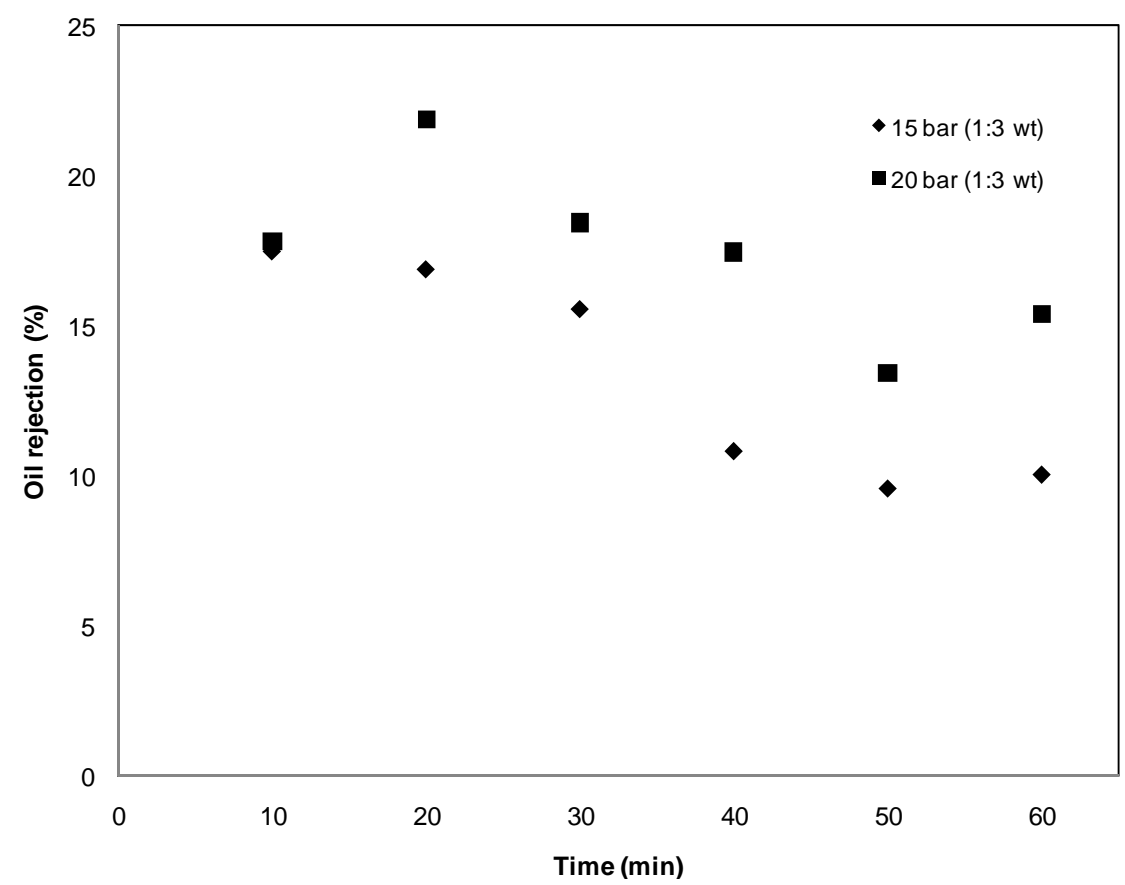

Fig. 6 Soybean oil rejection (\%) for NF 90 membrane, feed concentration 1:3 (oil/n-hexane).

Sepa GM (1:3 oil:hexane) and Sepa PT, which present larger pores and thus lower concentration polarization when compared to the other two membranes.

The behavior of rejection with transmembrane pressure did not show a clear tendency. Surprisingly, NF90 presented lower rejections than Sepa GM and
Sepa PT. This effect might be related with the membrane material and more pronounced plasticization and swelling of the membrane by the oil. In fact, when NF90 and Sepa GE membranes were observed after permeation they were translucent, which is an indication of plasticization. 


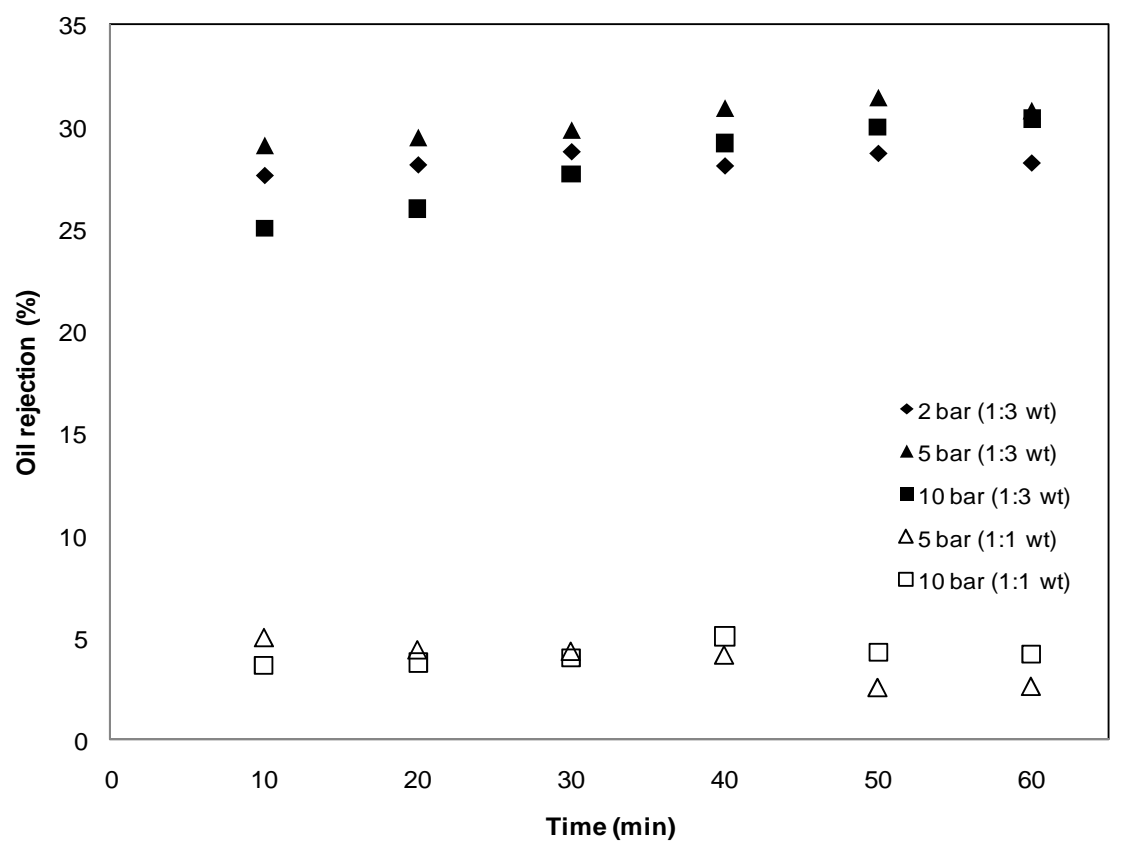

Fig. 7 Soybean oil rejection (\%) for Sepa GM membrane.

The oil rejections, permeate fluxes for oil and $\mathrm{n}$-hexane at 60 minutes of permeation are listed in Table 3. It is interesting to note that the oil rejections of Sepa GE were all negative in the permeation conditions tested, indicating that the membrane is selective for hexane. This is an unexpected behavior and could be also due to membrane plasticization. This hypothesis is strengthened by the fact that Sepa PT also showed rejection to solvent when the concentration of oil was increased (1:1 ratio). In addition, the oil rejection of NF90 decreased with time until negative rejections were found at 25 bar.

Both instantaneous and steady-state negative rejection coefficients have been reported in the literature. Le and Howell [23] observed and discussed instantaneous negative rejection coefficient even though the cumulative average rejection coefficient was always positive. They employed a dynamic pore blocking and unblocking concept to explain the unsteady-state transmission greater than $100 \%$. Balakrishnan et al. [24] were the first to report steady-state protein transmission greater than $100 \%$. They explained their steady-state findings by a combined concentration polarization-irreversible thermodynamics approach. They modified the concentration polarization model by adding an additional transport term representing solute migration due to attraction between the charged protein and the hydrophilic membrane. However, in order to explain different trends in observed transmission through membranes of various molecular weight cut-offs (but having the same membrane material), they were forced to vary the magnitude of this additional transport term. Karode et al. [25] developed a model capable to predict the permeate concentration in the protein ultrafiltration if the transport parameters through the membrane are known a priori. The model was verified against literature experimental data and was shown to be capable of predicting the observed protein transmission over the entire range of permeate flux. This new model also explains the steady-state transmission for some protein greater than $100 \%$.

The increase in the concentration of oil in the feed caused a decrease in the oil rejections for Sepa GM and Sepa PT membranes. Usually, when feed concentration is raised, an increase in rejection would be expected, due to higher fouling and concentration polarization [6]. Nevertheless, if swelling and plasticization takes place, 
Table 3 Oil rejection and permeate fluxes for soybean oil and $n$-hexane $\left(J_{p}\right)$ for all experimental conditions.

\begin{tabular}{|c|c|c|c|c|c|}
\hline \multicolumn{6}{|c|}{ Oil: $\mathrm{n}$-hexane ratio = 1:3 (wt) } \\
\hline Membrane & Feed pressure (bar) & $\begin{array}{l}\text { Oil rejection } \\
(\%)\end{array}$ & $\begin{array}{l}J_{P} \text { soybean Oil }\left(\mathrm{g} / \mathrm{m}^{2}\right. \\
\mathrm{h})\end{array}$ & $\mathrm{J}_{\mathrm{P}} \mathrm{n}$-hexane $\left(\mathrm{g} / \mathrm{m}^{2} \mathrm{~h}\right)$ & $\begin{array}{l}\mathrm{J}_{\mathrm{P}} \text { total } \\
\left(\mathrm{g} / \mathrm{m}^{2} \mathrm{~h}\right)\end{array}$ \\
\hline \multirow{3}{*}{ Sepa GE } & 15 & -13.0 & 49.4 & 83.0 & 132.3 \\
\hline & 20 & -7.7 & 34.0 & 61.7 & 95.7 \\
\hline & 25 & -30.4 & 28.9 & 38.3 & 67.2 \\
\hline \multirow{3}{*}{ Sepa GM } & 2 & 28.2 & 153.2 & 493.5 & 646.7 \\
\hline & 5 & 30.8 & 285.9 & 965.8 & 1251.7 \\
\hline & 10 & 30.4 & 321.6 & 1078.5 & 1400.2 \\
\hline \multirow{3}{*}{ Sepa PT } & 2 & 22.3 & 107.2 & 310.6 & 417.8 \\
\hline & 5 & 30.2 & 209.3 & 699.9 & 909.2 \\
\hline & 10 & 22.0 & 253.6 & 731.8 & 985.3 \\
\hline \multirow{3}{*}{ NF 90} & 15 & 10.0 & 64.7 & 153.2 & 217.8 \\
\hline & 20 & 15.4 & 79.9 & 206.3 & 286.3 \\
\hline & 25 & -10.4 & 73.2 & 127.6 & 200.8 \\
\hline \multicolumn{6}{|c|}{ Oil : n-hexane ratio $=1: 1(w t)$} \\
\hline \multirow{3}{*}{ Sepa GE } & 15 & -15.9 & 85.1 & 61.7 & 146.8 \\
\hline & 20 & -12.0 & 105.5 & 83.0 & 188.5 \\
\hline & 25 & -9.1 & 86.8 & 72.3 & 159.1 \\
\hline \multirow{3}{*}{ Sepa GM } & 2 & -2.6 & 127.6 & 121.2 & 248.9 \\
\hline & 5 & 2.6 & 270.6 & 285.0 & 555.6 \\
\hline & 10 & 4.2 & 617.8 & 672.2 & 1290.0 \\
\hline \multirow{3}{*}{ Sepa PT } & 2 & -52.4 & 27.2 & 8.5 & 35.7 \\
\hline & 5 & -7.2 & 132.7 & 114.9 & 247.6 \\
\hline & 10 & -2.3 & 158.3 & 151.0 & 309.3 \\
\hline
\end{tabular}

the rejection might drop due to the loss of membrane selective properties. The increment in pressure increases the oil concentration on membrane surface, possibly intensifying the effects of swelling and plasticization, causing the membranes to lose their selectivity. When swelling and plasticization occurs, transport properties are difficult to establish [26], since the membrane material will also play an important role on the membrane performance. The transport is also affected by other parameters such as surface tension and solubility parameter of the permeating solvent [27]. Tres et al. [12] showed that the membrane surface properties can change to a large extent, after permeation of a miscella of soybean oil with n-hexane and with liquid n-butane.

The feed pressure seems to exert a positive effect on oil fluxes for most of the studied conditions. The Sepa GE and NF90 showed a different behavior, i.e., the dependency of flux on operating transmembrane pressure seems to depend on the concentration of feed. For Sepa GM and PT, the increase in pressure is followed by an increase in both fluxes, but this relation is linear up to 5 bar. Further increase in pressure cause the fluxes to reach a limiting flux. This behavior is characteristic of concentration polarization and fouling, as previously mentioned.

\section{Conclusions}

In this work the separation of refined soybean oil/n-hexane miscellas was studied using different commercial membranes, with saline rejection and MWCO ranging from $>97 \% \mathrm{MgSO}_{4}$ and 1 to $5 \mathrm{kDa}$. The membrane Sepa GM (4 kDa) presented the highest rejections $(>30 \%)$ and permeate fluxes $\left(>1500 \mathrm{~g} / \mathrm{m}^{2}\right.$ h). Results obtained in this work show that polymeric membranes, thus showing a potential for industrial applications, can separate refined soybean oil/n-hexane miscellas. 


\section{Acknowledgments}

The authors thank Intecnial S.A., URI-Campus de Erechim, CNPq for financial support and scholarships.

\section{References}

[1] J.B. Snape, M. Nakajima, Processing of agricultural fats and oils using membrane technology, J. Food Eng. 30 (1996) 1-46.

[2] L.A. Johnson, E.W Lusas, Comparison of alternative solvents for oils extraction, J. Am. Oil Chem. Soc. 60 (1983) 229-242.

[3] J.A.A. Savasini, M.H.G.P. Zockun, P.M.M.D. Ferreira, Industrialização da soja, in: S. Miyasaka, J.C. Medina (Eds.), A Soja no Brasil, Campinas: ITAL 1981, pp. 916-920.

[4] T.G. Kemper, Solvent recovery and loss management, in: P.J. Wan, P.J. Wakelyn (Eds.), Technology and Solvents for Extracting Oilseeds and Nonpetroleum Oils, 1997, pp. 148-152, Champaign: AOCS Press.

[5] E.L.S. Zanetti, Industrialização da soja, in: S. Miyasaka, J. C. Medina (Eds.), A soja no Brasil, Campinas: ITAL, 1981.

[6] M. Mulder, Basic Principles of Membrane Technology, 2nd ed., Kluwer Academic Publishers, 2000.

[7] A.P.B. Ribeiro, N. Bei, L.A.G. Gonçalves, J.C.C. Petrus, L.A. Viotto, The optimization of soybean oil degumming on a pilot plant scale using ceramic membrane, J. Food Eng. 87 (2008) 514-521.

[8] C.M. Coutinho, M.C. Chiu, R.C. Basso, A.P.B. Ribeiro, L.A.G. Gonçalves, L.A. Viotto, State of art of the application of membrane technology to vegetable oils: A review, Food Res. Int. 42 (2009) 536-550.

[9] S.S. Köseoğlu, J.T. Lawhon, E.W. Lusas, Membrane processing of crude vegetable oils: Pilot plant scale removal of solvent from oil miscellas, J. Am. Oil Chem. Soc. 67 (1990) 315-322.

[10] M.V. Tres, S. Mohr, M.L. Corazza, M. Di Luccio, J.V. Oliveira, Separation of n-butane from soybean oil mixtures using membrane processes, J. Membr. Sci. 333 (2009) 141-146.

[11] M.V. Tres, S. Mohr, M. Di Luccio, J.V. Oliveira, Low-pressure solubility of propane and n-butane in refined soybean oil, J. Chem. Thermodyn. 41 (2009) 1378-1381.

[12] M.V. Tres, H.C. Ferraz, R.M. Dallago, M. Di Luccio, J.V. Oliveira, Characterization of polymeric membranes used in vegetable oil/organic solvents separation, J. Membr. Sci. 362 (2010) 495-500.

[13] A. Koris, G. Vatai, Dry degumming of vegetable oils by membrane filtration, Desalination 148 (2002) 149-153.

[14] B. van der Bruggen, J. Geens, C. Vandecasteele, Fluxes and rejections for nanofiltration with solvent stable polymeric membranes in water, ethanol and $n$-hexane, Chem. Eng. Sci. 57 (2002) 2511-2518.

[15] C. Pagliero, N. Ochoa, J. Marchese, M. Mattea, Degumming of crude soybean oil by ultrafiltration using polymeric membranes, J. Am. Oil Chem. Soc. 78 (2001) 793-796.

[16] A.P.B. Ribeiro, J.M.L.N. Moura, L.A.G. Gonçalves, J.C.C Petrus, L.A. Viotto, Solvent recovery from soybean oil/hexane miscella by polymeric membranes, J. Membr. Sci. 282 (2006) 328-336.

[17] N. Ochoa, C. Pagliero, J. Marchese, M. Mattea, Ultrafiltration of vegetable oils degumming by polymeric membranes, Sep. Purif. Technol. 22-23 (2001) 417-422.

[18] L. Song. A new model for the calculation of the limiting flux in ultrafiltration, J. Mem. Sci. 144 (1998) 173-185.

[19] C.Y. Tang, J.O. Leckie, Membrane independent limiting flux for RO and NF membranes fouled by humic acid, Environmental Science and Technology 41 (2007) 4767-4773.

[20] A.C. Habert, C.P. Borges, R. Nobrega, Processo de separação por membranas, Rio de Janeiro: E-papers, 2006.

[21] R.W. Baker, Membrane Technology and Applications, 2nd ed., John Wiley \& Sons Ltd., England, 2004.

[22] L.A.V. Sarmento, C.T. Spricigo, J.C.C. Petrus, L.H.C. Carlson, R.A.F. Machado, Performance of reverse osmosis membranes in the separation of supercritical $\mathrm{CO}_{2}$ and essential oils, J. Membr. Sci. 237 (2004) 71-76.

[23] M.S. Le, J.A. Howell, An alternative model for ultrafiltration, Chem. Eng. Res. Des. 62 (1984) 373-380.

[24] M. Balakrishnan, G.P. Agarwal, C.L. Cooney, Study of protein transmission through ultrafiltration membranes, J. Membr. Sci. 85 (1993) 111-128.

[25] S.K. Karode, T. Courtois, M. Mietton-Peuchot, B.B. Gupta, Protein ultrafiltration: An explanation for negative rejection, J. Membr. Sci. 168 (2000) 75-85.

[26] V.E. Patil, L.J.P. van den Broeke, F.F. Vercauteren, J.T.F. Keurentjes, Permeation of supercritical carbon dioxide through polymeric hollow fiber membranes, J. Membr. Sci. 271 (2006) 77-85.

[27] D.R. Machado, D. Hasson, R. Semiat, Effect of solvent properties on permeate flowthrough nanofiltration membranes, Part I: Investigation of parameters affecting solvent flux, J. Membr. Sci. 163 (1999) 93-102. 